\title{
Los otros ciudadanos: Asociacionismo, prensa y política de los negros montevideanos \\ a fines del siglo XIX
}

Gustavo Goldman

Universidad de la República

Recibido: 30/04/2016

Aceptado: 04/ 06/ 2016

Resumen. El artículo trata sobre cómo algunos grupos de la población afrodescendiente se organizaron y entablaron diferentes acciones políticas en la ciudad de Montevideo durante el año electoral de 1872. La paz, acordada en abril de ese año, que puso fin a la conocida como Revolución de las Lanzas, auspició —al menos entre algunos grupos de intelectuales - un cambio en la forma de pensar y dirimir las diferencias políticas. Dos organizaciones de negros montevideanos jugaron un rol protagónico en este contexto: el Club Igualdad y el Club Defensa. Ambos mostraron, a través de sus presencias en la prensa escrita montevideana, la tensión que existía en ese momento histórico entre tradición y modernidad en los proyectos de construcción de la ciudadanía.

Palabras claves: Ciudadanía - afrodescendientes - organizaciones

\begin{abstract}
This article seeks insight into the way some groups of African descent organization established diverse political actions in the city of Montevideo during the electoral year of 1872. Peace which was agreed in April that year to end the Revolución de las Lanzas, fostered --at least within some groups of intellectuals-- a change in the way to think and to settle political differences. Two Montevidean black organizations played a leading role in this context: Club Igualdad and Club Defensa. Both of them showed through their involvement in the Montevidean written press the existing tension at that time between tradition and modernity regarding citizenship awareness.
\end{abstract}

Keywords: Citizenship - african descendants - organizations 


\section{Introducción}

El fin de la esclavitud en el Río de la Plata trajo aparejado un cambio en las formas de incorporación de la población de origen africano a las estructuras sociales, económicas y políticas republicanas. En este contexto, formas asociativas de carácter religioso -como las cofradías- y de tipo étnico -como las salas o sociedades africanas- comenzaron en buena medida a ser reconfiguradas o sustituidas por nuevas formas asociativas como producto de la adhesión de sectores de afrodescendientes a los procesos de modernización del Estado. ${ }^{1}$

La prensa de los afro-descendientes planteaba con claridad que la libertad había abierto las puertas a un cambio de mentalidad y a la participación activa de los afro-descendientes en la sociedad. Así lo expresaba un periodista de La Conservación, hasta ahora, el primer periódico del que se tienen noticias, dirigido y redactado por un grupo de afro-descendientes montevideanos: "Ayer bullía en la mente de todas las personas de color las aspiraciones de libertad. Hoy nuestros pensamientos sólo son de ilustración. Ayer sólo reinaba la humildad. Hoy sólo se piensa en llegar al término del camino en nuestras aspiraciones". ${ }^{2}$

En un contexto general de explosión asociativa, algunos grupos de negros montevideanos comenzaron a nuclearse -a fines de las década del sesenta del siglo XIX- en asociaciones que perseguían distintos fines: culturales, mutuales, recreativos y políticos ${ }^{3}$. El estudio de estas formas asociativas voluntarias abre una ventana al conocimiento de la acción organizada de algunos grupos de afro-descendientes. Estos entendieron, en la segunda mitad del siglo XIX - cuando las ideas de civilización y progreso vinculadas a la consolidación y expansión del capitalismo eran paradigmáticas para los grupos hegemónicos- que en la asociación estaba el camino para alcanzar una posición de igualdad en la sociedad.

El fin de la Guerra Grande y la caída de Rosas marcan en el Río de la Plata una frontera clara entre un antes y un después, reflejada en la prensa de la población de origen africano a través de títulos como Ayer y hoy o El pasado y el presente. El "hoy" representado por el progreso, la civilización y la ilustración en un contexto

1 GOLDMAN, Gustavo, Lucamba: herencia africana en el tango (1870-1890), Montevideo, Perro Andaluz Ediciones, 2008, p. 28.

22a Conservación, Año I, núm. 4, Montevideo, 25 agosto 1872.

${ }^{3}$ GOLDMAN, Gustavo, ob. cit., pp. 15-16. 
romántico de construcción de los estados nacionales, y el "ayer" referido a la "ignorancia de sus padres", la esclavización, la barbarie y las prácticas políticas de los caudillos. ${ }^{4}$

El dominio de la lectoescritura y la creación de órganos de prensa vinculados a las nuevas formas asociativas caracterizaron la cultura social y política de estos afrodescendientes que pugnaban, de esta manera, por convertirse en ciudadanos y participar como tales. La campaña electoral del año 1872 constituye un emergente de esa actitud política. En un lapso de pocas semanas plantearon, desde los editoriales del periódico La Conservación -órgano de prensa surgido en el contexto políticoelectoral- la aspiración de presentar a la Cámara de Representantes un candidato afrodescendiente que defendiese sus intereses. Y luego, ante el fracaso de esta iniciativa, la intención de formar un "partido negro" independiente de los partidos existentes.

\section{Asociacionismo, prensa y política de los negros montevideanos}

El año 1872 es clave en el desarrollo de asociaciones políticas en las que participaron los afrodescendientes en Montevideo. Distintos tipos de conductas se pueden percibir en ese momento histórico, quedando al descubierto desde antiguas lealtades militares hasta diferentes formas de relacionamiento con los partidos políticos. La paz, acordada en abril de ese año que ponía fin a la conocida como Revolución de las Lanzas, había auspiciado —al menos entre algunos grupos de intelectuales- un cambio en la forma de pensar y dirimir las diferencias políticas. ${ }^{5}$

Según señala el historiador Juan Antonio Oddone, parecía que en ese momento se estaba cerrando un largo ciclo de cuatro décadas de guerras civiles que daba fin al también extenso proceso de ruptura de los lazos coloniales y que

\footnotetext{
4 La Conservación es recurrente al respecto. Ver editoriales de los días 4, 11 y 25 de agosto de 1872. Pilar GONZÁLEZ BERNALDO (2001), Norberto Pablo CIRIO (2009) y Lea GELER (2010) abordan esta temática para el caso de los afrodescendientes porteños. Véase las referencias completas en la bibliografía.

${ }^{5}$ La Revolución de las Lanzas fue un levantamiento armado liderado Timoteo Aparicio en contra del gobierno de Lorenzo Batlle, quien venía desplegando desde su asunción en 1868 una política de corte exclusivista y centralizada en Montevideo, que marginaba y perseguía a los caudillos blancos Véase BARRÁN, J osé Pedro, Apogeo y crisis del Uruguay pastoril y caudillesco. 1839-1875, Montevideo, Ediciones de la Banda Oriental, 2011, pp. 123-124.
} 
inauguraba una idea de reconstrucción política y administrativa ${ }^{6}$, que excluía las prácticas llevadas a cabo por los caudillos de los bandos colorado y blanco. ${ }^{7}$

A los pocos días de la Convención de Paz de 6 de abril de 1872, Fermín Ferreira y Artigas, en un discurso pronunciado en la Asamblea General, señalaba que había llegado el "momento de emprender la obra de regeneración social, de reconstruir legalmente los poderes públicos y de abrir un vasto horizonte para toda iniciativa de progreso y de adelanto moral y material". ${ }^{8}$

De ese momento político participaron dos asociaciones de negros montevideanos: el Club Igualdad y el Club Defensa; y fue durante ese año - entre los meses de agosto y noviembre-, que se publicó el periódico La Conservación, subtitulado como Órgano de la Sociedad de Color. ${ }^{9}$

Tal como describe Oddone, la campaña electoral del año 1872 adquirió una gran complejidad con la irrupción virulenta de las ideas liberales, que se sumaba al anhelo compartido por la pacificación definitiva del país. ${ }^{10}$ Se había generado, agrega este historiador, una reacción de los sectores juveniles e ilustrados contra las prácticas políticas de los bandos tradicionales, planteando a su vez nuevas fórmulas de convivencia política.

Luego de un período de festejos por la paz alcanzada, en el que se sucedieron una serie ininterrumpida de bailes y banquetes en los distintos barrios de Montevideo; en el mes de mayo la prensa comenzó a difundir la formación de diferentes clubes políticos que tendrían la función de afrontar la campaña electoral que se avecinaba. A inicios del mes de julio fue anunciada la apertura del registro

\footnotetext{
6 ODDONE, Juan Antonio, "El principismo del setenta: una experiencia liberal en el Uruguay", Montevideo, Instituto de Investigaciones Históricas/ FHC, 1956, p. 45.

7 ZUBIZARRETA, Ignacio y ETCHECHURY, Mario, “«Aquí no hay partidos»: estudios y perspectivas sobre las facciones y grupos políticos del siglo XIX hispanoamericano", en: Illes i Imperis, núm. 17, Barcelona, Universitat Pompeu Fabra, 2014, pp. 10-11. Los autores definen a las facciones o partidos formados en el siglo XIX en el Río de la Plata (blancos y colorados, o federales y unitarios) como coaliciones político-militares que se construyeron alrededor de liderazgos civiles o jefaturas militares de prestigio que actuaban en un amplio espacio geográfico.

8 El Ferro-carril, año IV, núm. 905, Montevideo, 10 abril 1872.

${ }^{9}$ ANDREWS, George Reid, Negros en la nación blanca: historia de los afrouruguayos, 1830-2000, Montevideo, Linardi y Risso, 2010, p. 59. Este autor señala que Marcos Padín y Andrés Seco habían fundado el periódico La Conservación con el propósito de darle mayor presencia y visibilidad política a la comunidad afrouruguaya.

10 ODDONE, J uan A., ob. cit., pp. 23-25.
} 
cívico convocándose a los ciudadanos a acudir a inscribirse. 11 Los partidos conformaban entonces comisiones o clubes barriales con el propósito de activar el proceso, sumar adherentes y, a su vez, contabilizar -a través del control de la confección del registro- las diferentes pertenencias políticas de los inscriptos en cada sección del departamento, en un sistema electoral ya de por sí restrictivo. ${ }^{12}$

El mes de mayo fue, entonces, el momento en el que se comenzaron a conformar los clubes políticos y durante el que se realizaron reuniones para elaborar sus respectivos programas de principios. El día 15 se realizó una reunión política en la casa de Antonio Solsona, a la que fueron convocados un gran número de miembros del Partido Colorado pertenecientes a las distintas facciones o círculos. Entre los asistentes a la reunión figuraron: el doctor Fermín Ferreira y Artigas, el general D. J osé A. Costa, Francisco X. Laviña, el doctor. J osé Pedro Ramírez, J osé Cándido Bustamante, el doctor Conrado Rücker, entre otros. Algunas personas se excusaron de asistir por diferentes razones; entre ellos, Francisco Bauzá, quien esgrimió estar ocupando el cargo de presidente de otro club en formación, el Club Liberal. A esa reunión asistieron al menos dos afrodescendientes: Andrés Seco y Manuel Gutiérrez. ${ }^{13}$

Andrés Seco, en un artículo escrito a más de veinte años después de los acontecimientos, aporta algunos datos que amplían la información. Antes de la aparición del periódico La Conservación se habría realizado una reunión en el Club Libertad del Partido Colorado, donde había hecho uso de la palabra José María

\footnotetext{
${ }^{11} \mathrm{El}$ Club Liberal, luego llamado Club Colorado, fue formado por colorados personalistas -afines a las prácticas de los caudillos políticos- también denominados netos o puros, y estaba presidido por Francisco Bauzá. El Club Libertad, integrado por principistas conservadores del Partido Colorado, era liderado por J osé Pedro Ramírez. Por otro lado, el Club Radical fue formado por principistas que se habían desvinculado de los partidos tradicionales como J osé Pedro Varela, y el Club Nacional, por principistas blancos como Agustín de Vedia (ODDONE, Juan A., ob. cit.).

${ }_{12}$ En el proceso electoral, que era largo y complejo, adquirían una importancia capital la elección de jueces de paz y tenientes alcaldes, quienes eran los que confeccionaban las listas de ciudadanos habilitados en los distritos y que conformaban el registro cívico (Elecciones de 1872, Publicación Oficial, Montevideo: Imprenta a Vapor de El Siglo, 1872).

Se abría un período de tachas en el que los grupos antagonistas pedían la exclusión de determinados ciudadanos por no cumplir con algunos de los requisitos constitucionales. Luego el ciudadano impugnado tenía derecho a solicitar su reincorporación al registro y finalmente los jueces de paz fallaban cada caso. Se puede realizar un seguimiento de este proceso y de las continuas acusaciones de fraude que se cruzaron los bandos, a través de la prensa partidaria (ver: Los Debates y La Democracia a partir del mes de agosto de 1872). Por ejemplo, la comisión de la quinta sección del Partido Colorado autodenominado puro o neto informaba a Francisco Bauzá, presidente de dicho partido, que en la sección se habían realizado, al día 26 de julio, seiscientas treinta y siete inscripciones, de las que cien pertenecían al Partido Nacional (Los Debates, año II, núm. 306, Montevideo, 26 julio 1872).

${ }^{13}$ El Ferro-carril, año I, núm. 931, Montevideo, 16 mayo 1872.
} 
Rodríguez. ${ }^{14}$ Según Seco, el discurso de Rodríguez fue un llamado a la unión del colectivo afrodescendiente: "Si en nuestra sociedad hay corazones que laten al impulso de una idea regeneradora: ¿qué hacemos que no armonizamos esa misma idea con el propósito de un buen fin junto con aquellos que como parias viven entre nosotros?". 15

Probablemente, la intervención de J osé María Rodríguez haya auspiciado la idea de proponer su nombre para integrar las listas del Partido Colorado a la Cámara de Representantes en las elecciones de noviembre de 1872. A partir de ese momento, comenzaron a sucederse algunos acontecimientos que muestran cómo algunos grupos de afrodescendientes participaron de diferentes maneras en negociaciones tendientes a establecer alianzas políticas con el fin de llevar a cabo este propósito, inédito hasta el momento, que finalmente no llegó a concretarse.

Algunas desavenencias internas, falta de pericia en el terreno político, posibles manipulaciones de los dirigentes de los círculos colorados, actitudes discriminatorias y los propios cambios que se fueron produciendo, constante y rápidamente durante esa campaña electoral, fueron colocando las aspiraciones políticas de estos grupos de afrodescendientes en un lugar cada vez más marginal.

En el mes de julio se fundaron dos asociaciones: el Club Igualdad y el Club Defensa. A su vez, a mediados de ese mes, la prensa montevideana anunciaba -a través de la reproducción del contenido de una hoja suelta-la aparición próxima del primer periódico dirigido por afrodescendientes.

El diario El Ferro-carril a mediados de julio de 1872 informaba sobre la publicación semanal "del primer órgano de la sociedad de color" y reproducía el programa que iba a llevar adelante su grupo editor y redactor, integrado por Marcos Padín, Andrés Seco y Agustín García. ${ }^{16}$ Allí se aclaraba que el periódico "no venía a

${ }^{14}$ J osé María Rodríguez fue un militar afrodescendiente que alcanzó el grado de sargento mayor y que participó, durante la Guerra Grande, de la defensa de Montevideo.

${ }^{15}$ La Propaganda, año I, núm. 5, Montevideo, 1o octubre 1893.

16 El Ferro-carril, año IV, núm. 981, jueves 18 y viernes 19 julio 1872. Lea GELER (2010) utiliza la categoría de intelectual subalterno para referirse a los letrados negros que pugnan por ocupar un lugar en la esfera pública. En el caso montevideano, los periodistas de La Conservación pertenecían a lo que George Reid ANDREWS para el caso de los afrobonaerenses denomina "clase media negra" (1989, ob. cit., p. 223). La revisión de las guías generales de 
hacer profesión de fe política" y que solo perseguía el objetivo de defender "los derechos únicos que nos corresponden como ciudadanos de esa misma sociedad a la que pertenecemos". ${ }^{17}$

Sin embargo, a los pocos días de este anuncio, comenzaron a sucederse una serie de hechos que ubicarían al periódico como sostenedor de una posición en la contienda electoral que se iniciaba. En el editorial del primer número, firmado por Andrés Seco, se ratificaba la independencia política al advertir a sus lectores que:

“[No venían] a la prensa a sostener caprichos de personas que basadas en uno u otro punto de nuestro programa quieran transformar nuestras doctrinas en ideas políticas. Solo venimos a presentar un bálsamo a aquellos débiles de corazón que fortalezca sus fibras debilitadas por la ignorancia". ${ }^{18}$

A continuación de ese editorial aparece un artículo titulado “Una ojeada sobre nuestra sociedad”, donde se aludía a la formación reciente de un club, sin mencionar el nombre, que tenía por objeto llevar a la Cámara de Representantes a una persona que defendiera los intereses de los afrodescendientes. ${ }^{19}$

\begin{abstract}
"Hemos tenido ocasión la noche del 20 pasado a una de esas grandes expansiones de nuestra sociedad, en honor del Sr. Rodríguez, uno de los iniciadores de ese club que se establece con el objeto de llevar a la Representación Nacional, un hombre que nos dignifique. Y francamente, lo decimos de todo corazón que nos sentimos henchidos de orgullo al ver que al fin se levantó un hombre de nuestra sociedad de color que hiciera oír su palabra en medio de una asamblea tan numerosa como era la que ocupaba el teatro esa noche". 20
\end{abstract}

A los pocos días de constituido ese club, que se llamó significativamente Club Igualdad, el diario Los Debates, dirigido y redactado por Pedro E. Bauzá y Francisco

comercio y particulares del período ubica a personajes como Marcos Padín y Andrés Seco como propietarios de sus casas (Guía General Comercial de La Tribuna para el año 1877, Montevideo, Imprenta a vapor de La Tribuna, 1877).

${ }^{17}$ Ibíd.

18 La Conservación, año I, núm. 1, Montevideo, 4 agosto 1872.

19 El 3 de agosto de 1872 se realizó la elección de autoridades del Club Igualdad (La Conservación, año I, núm. 3, Montevideo, 18 agosto 1872).

${ }^{20} \mathrm{La}$ Conservación, año I, núm. 1, Montevideo, 4 agosto 1872. 
Bauzá -ambos colorados netos o puros- daba cuenta de su conformación e informaba lo siguiente:

"[el diario tenía como objeto principal el reunir fondos para sostener una publicación que sirviera] de órgano de los sentimientos e intereses del pueblo moderado (vulgarmente de color), que sostenga sus derechos y garantías y reclame la libertad e independencia individual o proteste solemnemente contra la usurpación, sin olvidar en su benéfica propaganda los verdaderos intereses del país". ${ }^{21}$

Para poder llevar adelante estos propósitos, los responsables del club planeaban la adquisición de una imprenta donde se pudieran realizar trabajos particulares con el fin de sostener financieramente el periódico y, a su vez, armar una biblioteca para el uso de sus asociados. También planteaban que el club debía "marchar ajeno a los partidos políticos nacionales y extranjeros" y "abrazar todo aquello que crea lícito y consecuente a su más grande y justa aspiración a la igualdad". 22

La dirección del Club Igualdad quedó constituida de la siguiente manera: Presidente, don J osé María Rodríguez; Vicepresidente, J osé C. Gutiérrez; Secretario, Luis González; Subsecretario, Enrique Munn; Cajero, Cipriano Lima; Bibliotecario interino, J osé C. Gutiérrez; Vocales, Patricio M. López, Apolinario Blanco y Mariano Martínez; y Comisión Fiscal, Don Saturnino Lara y Manuel Gutiérrez".23

El periódico La Conservación realizó -ininterrumpidamente a partir de su primer número - una continua propaganda a favor del Club Igualdad, resaltando expresamente el rol de J osé María Rodríguez como líder del impulso de progreso social y regeneración de la "clase de color".

A medida que se iba acercando la fecha de las elecciones comenzaron a aparecer una serie de editoriales bajo el título "Nuestro candidato", en los que se apoyaba plenamente la idea de proponer a J osé María Rodríguez como candidato a

\footnotetext{
${ }^{21}$ Los Debates, año II, núm. 319, Montevideo, 10 agosto 1872.

22 Ibíd.

23 Ibíd.
} 
ocupar un lugar en la Cámara de Representantes. Entre las virtudes que el periódico atribuía a Rodríguez resaltaba, con énfasis, su calidad de militar. ${ }^{24}$

El 28 de julio tuvo lugar la primera reunión preparatoria de instalación de otro club electoral de la "gente de color". 25 Esta vez, bajo una denominación que aludía claramente a la Defensa de Montevideo durante la Guerra Grande. El Club Defensa se presentaba a la opinión pública como una "asociación política de todos los ciudadanos de color que simpatizan con las elevadas y patrióticas ideas del Partido Colorado". Según expresaba El Ferro-carril, el Club Defensa aceptaba como suyo el programa del Club Libertad y entraba a la lucha electoral con el propósito de sostener una candidatura surgida del "seno de su comunidad". ${ }^{26}$ Además, se explicitaba que en ningún caso se iba a aceptar alianza o fusión alguna con el Partido Blanco, "cuyos resultados han sido siempre contraproducentes y funestos". Por último, realizaba una mención —como valor político—a la "epopeya que inmortalizó la Defensa de Montevideo".

La comisión directiva de la asociación quedó —según informaba El Ferrocarril — constituida de la siguiente manera: Presidente, teniente coronel Feliciano González; Vicepresidente, teniente coronel Isidoro Carrión; Secretarios, sargento mayor J osé María Rodríguez y ciudadano Luis González; Vocales, teniente coronel Silvestre Farías, sargento Floro A. Madriaga, teniente Agustín Berón, ciudadano Rafael Gallego, ciudadano Pedro Fortes, ciudadano José B. Brandón, ciudadano Pedro Rodríguez y ciudadano J osé G. Pérez. ${ }^{27}$

El Club Defensa estaba conformado, entonces, por militares afrodescendientes que en su mayoría habían participado de la Defensa de Montevideo y también por algunos civiles. Como expresa el texto del programa reproducido por el diario El Ferro-carril, uno de los objetivos del club, que se había constituido como una "sucursal del Libertad, centro del Partido Colorado", fue el de postular a la representación nacional a un afrodescendiente.

${ }^{24}$ Ver La Conservación, 29 de setiembre, 6, 13, 20 y 27 de octubre y 6, 10, 17 y 24 de noviembre de 1872.

${ }^{25}$ El Ferro-carril, año IV, núm. 990, Montevideo, 30 julio 1872.

${ }^{26}$ El Ferro-carril, año IV, núm. 990, Montevideo, 30 julio 1872.

${ }^{27}$ Ibíd. Es llamativo que tanto el Club Defensa como el Club Igualdad tuvieran como secretario a una persona de nombre Luis González. 
Por lo que se desprende del análisis de la prensa consultada, fue el Club Defensa el que llevó adelante las negociaciones con el Club Libertad con miras a la presentación de un candidato afrodescendiente a la Cámara de Representantes.

\title{
La candidatura de J osé María Rodríguez
}

Hasta mediados de setiembre, el club no había tomado la decisión respecto de la persona que se iba a proponer. En una reunión llevada a cabo a inicios de ese mes, con motivo de despedir a Feliciano González — que iba a emprender un viaje a Callao-, tomó la palabra el sargento Floro A. Madriaga, quien señaló la urgencia de elegir a un hombre que representara los intereses de la "clase de color".

Según Madriaga, el fallecimiento del doctor Fermín Ferreira y Artigas había precipitado $\rightarrow$ al menos en un grupo de miembros del club- la idea de elegir a un afrodescendiente para esa postulación. Decía Madriaga en esa oportunidad:

\begin{abstract}
"Hoy, señores, se halla en la mansión de los justos el hombre que muchos de mis compañeros tenían fija su vista en él. Hablo del Tribuno Oriental, del amigo del pueblo, doctor Don Fermín Ferreira y Artigas. Dios lo ha llamado a su seno: paz en su tumba. Debemos fijarnos en la elección de algún otro. No echemos en olvido nuestra conveniencia; al señor presidente toca no dejar por más tiempo el hacer conocer el hombre que debe de representarnos.”. 28
\end{abstract}

Una carta que un afroporteño -mencionado como R. Mendizábal- enviara a José Gutiérrez fue transcripta -a pedido de este último- por La Conservación. Gutiérrez, al reenviar la carta para su publicación en el periódico, presentaba a Mendizábal como un "joven de nuestra raza bastante aventajado y que actualmente es el director de El Mercantil de Buenos Aires”. 29 Mendizábal, además de preguntar sobre los fines políticos del periódico, proponía el nombre de un posible candidato como representante del colectivo afrodescendiente a ocupar un cargo en la Cámara de Representantes. Dice Rodolfo E. Mendizábal:

\footnotetext{
${ }^{28}$ Los Debates, año II, núm. 343, Montevideo, 10 setiembre 1872.

29 La Conservación, año I, núm. 6, Montevideo, 8 setiembre 1872. En el diario El Mercantil de Buenos Aires figuraba como director R. E. Mendizábal, y algunos artículos son firmados por Rodolfo E. Mendizábal. Por otra parte, en el año 1874 Rodolfo E. Mendizábal publicó en Buenos Aires La política del porvenir. Artículos al correr de la pluma. Publicados en El Mercantil. Es interesante notar que la carta de Rodolfo Emilio Mendizábal estaba fechada en Buenos Aires el día 20 de agosto, apenas transcurridas dos semanas de la aparición del primer número de La Conservación.
} 
“Hay algunos hombres que ayudan [a] su propaganda, que se manifiestan simpáticos al esfuerzo de dar al hombre de color su posición al nivel de los demás miembros sociales. Pues bien ustedes, que forman una sociedad exclusiva, reunida en un solo propósito, pongan a prueba la sinceridad de aquellos, reclamando para un candidato sus votos y sus simpatías. Me parece que, por ahora, don Feliciano González [el énfasis es del autor] sería una personalidad aparente para iniciar esa nueva resurrección de Lázaro”. ${ }^{30}$

Feliciano González ${ }^{31}$ era un militar que tenía una dilatada y reconocida actuación desde principios de la década de 1840 y que además estaba vinculado a los sectores autodenominados como netos del Partido Colorado. ${ }^{32}$ Pero para que Feliciano González - lo mismo que J osé María Rodríguez u otro militar — pudiera ser candidato a la representación nacional, debía primero —cuestión que dependía de su decisión personal-pedir la baja en el ejército. 33 Pero, además, Feliciano González no iba a estar presente para la fecha de las elecciones pues habría de emprender un viaje a la ciudad de Callao a bordo del vapor Patagonia. 34

Lo cierto es que la candidatura apoyada por el Club Defensa y el Club Igualdad recayó sobre el sargento mayor J osé María Rodríguez, miembro —como ya se ha mencionado-de ambos clubes. ${ }^{35}$

\footnotetext{
30 La Conservación, año I, núm. 6, Montevideo, 8 setiembre 1872. Es interesante notar que Rodolfo E. Mendizábal era hijo de Rosendo Mendizábal, un militar afroporteño antirrosista que en Montevideo participó del Gobierno de la Defensa, donde probablemente haya tomado contacto con Feliciano González. En el diario El Nacional de Buenos Aires, Domingo Faustino Sarmiento realiza una semblanza de Rosendo Mendizábal en la que destaca su actuación durante la época rosista (El Nacional, Año VII, núm. 1865, Buenos Aires, 15 enero 1858).

${ }^{31}$ Según Fernández Saldaña, Feliciano González fue un militar que tuvo una destacada actuación en el ejército a partir del año 1843, siendo probablemente uno de los esclavos manumitidos en diciembre de 1842. Por su actuación como integrante de la división oriental en la campaña de Caseros, el gobierno le concedió una medalla de plata. Luego del fracaso del levantamiento que culminó con los fusilamientos en Quinteros a comienzos de 1858 emigró al territorio argentino, donde continuó su carrera militar participando en los combates de Cepeda y Pavón. Participó también -aunque tardíamente- de la revolución de Venancio Flores y luego en la guerra contra el Paraguay. Obtuvo el grado de coronel en diciembre de 1894. (FERNÁNDEZ SALDAÑA, J osé María, Diccionario uruguayo de biografías, 1810-1940, Montevideo, Editorial Amerindia, 1945, p. 596).

32 Los Debates, año II, núm. 308, Montevideo, 24 julio 1872.

${ }^{33}$ El diario Los Debates publica lo siguiente: La clase militar debe tener representantes en la Asamblea como los tienen todas las otras clases de la sociedad. Es absurdo exigir de un ciudadano que soporte todas las cargas sin concederle ninguno de los beneficios (Los Debates, año II, núm. 307, Montevideo, sábado 23 julio 1872).

${ }^{34}$ Los Debates, año II, núm. 343, Montevideo, 10 setiembre 1872. El diario El Ferro-carril, ese mismo día, bajo el título "Una cuadrilla de morenos", daba cuenta de que para mediados de diciembre se iba a estar presentando una cuadrilla de toreros morenos que Feliciano González había ido a contratar en el Perú (El Ferro-carril, año IV, núm. 1014, Montevideo, 10 setiembre 1872).

35 Dos personas aparecen formando parte de la directiva del Club Igualdad y del Club Defensa al mismo tiempo: el sargento mayor J osé María Rodríguez, quien ocupaba el cargo de presidente del
} 
El día 22 de setiembre La Conservación anunció finalmente, de manera explícita, su apoyo a José María Rodríguez, instando a votar por él. En estos términos señalaba la responsabilidad que le cabía a la generación de afrodescendientes en esa coyuntura: "Si en la época de moral, libertad y garantías que atravesamos no ejercemos nuestros derechos de ciudadanos. ¿Para cuándo queda nuestra reconstrucción?”. ${ }^{36}$

Ese mismo día había tenido una reunión muy peculiar en el local de la calle Reconquista número 105 del Club Defensa a la que asistieron algunos miembros del Partido Colorado. Seguramente esta asistencia haya tenido el fin, según se puede desprender de los datos aparecidos en la prensa, de concretar algunas negociaciones establecidas, tal vez anticipadamente, entre algunos miembros del Club Libertad y del Club Defensa. Según el diario Los Debates, el primero que hizo uso de la palabra fue el presidente del club, Feliciano González, quien propuso que se iniciara una suscripción con el fin de erigir una estatua ecuestre "al ilustre brigadier general don Venancio Flores”. Para fundamentar su planteo, González resaltó la figura de Flores y la parangonó con la de J osé de San Martín:

"A todos los hombres beneméritos entre los países del mundo se han levantado monumentos, ya al mérito, ya al valor por sus conciudadanos. Que sin ir más lejos nuestra hermana la República Argentina le había erigido el suyo al general San Martín. Por consiguiente nosotros haremos un deber desde este momento de promover una suscripción para que se haga una estatua al hombre que nos ha dado la patria, el General don Venancio Flores en el traje con que se ha visto entrar en Montevideo después de la Cruzada Libertadora en la Plaza que lleva su nombre para que sirva de eterno recuerdo a las generaciones venideras y se sepa que los hombres de color que componen este Club Defensa somos agradecidos y sirva también de estímulo a los jóvenes de nuestra raza". ${ }^{37}$

La moción de Feliciano González fue aprobada por la asamblea, que nombró una comisión a los efectos de llevar adelante la suscripción para el referido monumento. Dicha comisión quedó constituida por Floro Madriaga, Agustín Berón y

primero y era secretario del segundo, y un ciudadano de nombre Luis González, quien actuaba como secretario en ambos clubes.

${ }^{36}$ La Conservación, año I, núm. 8, Montevideo, 22 setiembre 1872.

37 Los Debates, año II, núm. 359, Montevideo, 28 setiembre 1872. 
Pedro Fortes, quienes actuarían como tesoreros, y José Cándido Bustamante, señalado como "un fiel amigo", en el cargo de presidente. 38

Luego de aprobarse la propuesta de Feliciano González, el coronel Fortunato Flores, hijo de Venancio Flores, pidió permiso para tomar la palabra, mostrándose conmovido -según describe Los Debates-mientras expresaba su agradecimiento al presidente del Club Defensa por la iniciativa planteada. 39 A continuación, uno de los afiliados al Club Defensa pidió la palabra para proponer "al ciudadano coronel Flores fuese como candidato por los hombres de color a la representación nacional", a lo que el presidente del club, Feliciano González, contestó que al día siguiente (23 de setiembre) iba tener lugar una reunión particular para llevar a la representación nacional a un hombre de color: al mayor J osé María Rodríguez. ${ }^{40} \mathrm{~A}$ continuación, expresó una alternativa en caso de la no aceptación de J osé María Rodríguez a la candidatura:

"[Si no la aceptase] y no pudiese llevarse a otro de nuestra raza, proponía al ciudadano don Fortunato Flores como nuestro candidato reconociendo en él ideas nobles hasta hacer el sacrificio de pedir su baja absoluta únicamente para el bien de la clase de color y representarnos debidamente".

El domingo 20 de octubre se dio a conocer la lista que se debía apoyar, elegida por mayoría en una reunión celebrada en el local de redacción de La Conservación. Varios de los nombres que la integraban ocuparon luego cargos ministeriales durante el gobierno de J osé Ellauri. Los titulares de la lista elegida y publicada eran: J osé Pedro Ramírez, Adolfo Rodríguez, Pedro Bustamante, José María Rodríguez, Lino Herosa, Francisco Lecocq, J osé C. Bustamante, Fernando Torres, J uan C. Costa, J osé V. Gomensoro y Mariano Ferreira. Los suplentes eran: Aureliano Rücker, Isaac de Tezanos, Carlos María Ramírez, Fortunato Flores, Vicente Garzón, J aime Estrázulas, Amaro Carve, J osé Pedro Varela, Prudencio Ellauri, Alejandro Chucarro (hijo) y

\footnotetext{
38 Ibíd. A fines de setiembre es notorio un acercamiento de los sectores netos del Partido Colorado al Club Defensa. En el número correspondiente al día 24 de setiembre, la redacción de Los Debates, Francisco Bauzá y Pedro E. Bauzá, publicó un agradecimiento en nombre del Partido Colorado al Club Defensa, al director de La Tribuna y a todos los militares y ciudadanos que habían acompañado en un acto realizado el sábado 21 de setiembre.

39 El tema de la antigua lealtad militar a Venancio Flores surge con claridad de estos relatos.

40 Los Debates, año II, núm. 359, Montevideo, 28 setiembre 1872. El club compensaría el sacrificio que afrontaría J osé María Rodríguez al pedir su retiro militar, pagando el equivalente al sueldo que recibía por esa labor.
} 
Bernabé Herrera. ${ }^{41}$ El periódico presentaba la lista poniendo en "conocimiento del pueblo, que al haber elegido esta lista solo nos han guiado los sentimientos de libertad y democracia. Pensamientos que son los más sagrados de los pueblos porque de ellos es que depende el triunfo". 42

\section{Los hechos se precipitan}

Resulta necesario volver a revisar la situación política, pues ayudará a comprender el contexto en el que se daban todas estas negociaciones. El registro cívico se había cerrado el día 31 de agosto y a partir del mes de setiembre se sucedieron una serie de denuncias cruzadas de fraude en la confección de éste, realizadas principalmente por el Club Nacional.

La situación política se tornó bastante inestable pues el Club Nacional comenzaba a insinuar, cosa que finalmente concretó el día 9 de noviembre, su abstención en los comicios. Igual conducta asumió el Club Radical que, apoyando en un principio las denuncias realizadas por los nacionalistas, terminó —después de haber incitado desde el diario La Paz tanto a los principistas radicales como a los principistas blancos a votar por los candidatos principistas del Partido Coloradooptando también por la abstención. ${ }^{43}$

El panorama resultante para los comicios de noviembre terminó, hacia el final de la campaña electoral, con los sectores netos y principistas colorados como únicos contendientes en los comicios. El diario La Paz de José Pedro Varela calificó la situación a la que se había llegado como "la más violenta anarquía". ${ }^{4}$

Por su parte, J osé Pedro Ramírez, calibrando las posibilidades de los grupos principistas frente a los elementos personalistas dentro del Partido Colorado y también dentro del frágil equilibrio interno del Club Libertad, entendió que la opción más favorable era la confección de una lista mixta con mayoría principista pero encabezada por José Cándido Bustamante, uno de los personalistas del Club Libertad. La situación se estrechó aún más cuando José C. Bustamante y otros

\footnotetext{
${ }^{41}$ La Conservación, año I, núm. 12, Montevideo, 20 octubre 1872.

42 Ibíd.

43 ODDONE, J . A., ob. cit., p. 53.

${ }^{44}$ La Paz, segunda época, núm. 483, Montevideo, 18 noviembre 1872.
} 
colorados netos renunciaron al Club Libertad y se pasaron a las filas tradicionales del Partido Colorado. 45

Pero, ¿qué estaba pasando con el Club Defensa en esos momentos? En el diario El Ferro-carril aparecen algunos datos que permiten una aproximación al conocimiento de la postura política tomada por dicho club. El día 11 de octubre la directiva del Club Defensa, liderada por Isidoro Carrión, envió una carta al Club Libertad. Informaba que en la asamblea general del club se había proclamado por unanimidad la postulación del sargento mayor José María Rodríguez, quien a los efectos iba a solicitar su separación de la carrera de las armas. ${ }^{46}$

“Duro y penoso a la vez, Sr. presidente es el sacrificio que se impone el Sr. Rodríguez, pero también orgullo será para el partido que representamos el ser el primero que en la Representación Nacional eleve a un hombre de color como representante de una raza hasta hoy vilipendiada y oscurecidos sus hechos por sus enemigos". ${ }^{47}$

La carta finalizaba con la solicitud al Club Libertad de la inclusión de José María Rodríguez en las listas a presentar en las elecciones de noviembre. El diario El Ferro-carril publicó, de manera destacada en la portada del día 19 de octubre, la carta de respuesta fechada el día 18 y firmada en nombre del Club Libertad por Pedro Carve y J uan A. Magariños Cervantes.

A pesar de que la comisión directiva del Club Libertad consideraba -dice la misiva- muy plausible el anhelo del Club Defensa, comunicaba que no tenía la facultad de formar listas ni de someterlas al pueblo:

\footnotetext{
“Estas [las comisiones seccionales], como la Comisión Directiva del Club Defensa y como cualquier ciudadano puede formar listas y publicarlas y prestigiarlas por los medios legítimos de propaganda y de persuasión, y la votación hecha oportunamente dirá cuáles candidaturas debe hacer suyas esta comisión para prestarles todo el concurso de la investidura popular que ha recibido del Club". ${ }^{48}$
}

La nota continuaba invitando al Club Defensa a reconocer y a acatar -en nombre de la igualdad de derechos y de deberes-las resoluciones del Club Libertad,

45 ODDONE, J . A., ob. cit., p. 58.

46 El Ferro-carril, año IV, núm. 1044, Montevideo, 16 octubre 1872.

${ }^{47}$ Ibídem.

48 El Ferro-carril, año IV, núm. 1047, Montevideo, 19 octubre 1872. 
club que no podía "dejar de hacer prevalecer en cumplimiento del mandato recibido y de sus propias convicciones".

La contestación del Club Defensa llegó nueve días después, el día 20 de octubre. En la nota, firmada por Isidro Carrión, se aclaraba que

"El Sr. Rodríguez no se ha comprometido en este club a pedir su baja y separación absoluta al Ejército de la República, sino que habiéndose rechazado a hacerla hasta por tercera vez, la comisión especial encargada de manifestarle la resolución del club le pidió que dentro de algunos días contestase y creyendo esta comisión directiva que después de reflexionar no persistiría el Sr. Rodríguez en no hacer el doloroso sacrificio que se le exigía en holocausto a los intereses, derechos y estímulo de nuestra clase, creyó conveniente pasar la citada nota y prevenir incidentalmente a esa Comisión para tener asiento en las bancas parlamentarias, pediría su separación de las armas". 49

Según se expresa en la carta, la respuesta definitiva de J osé María Rodríguez -que no aparece nunca hablando en primera persona en estos intercambios- fue que no iba a renunciar a su calidad de militar, mostrándose a la vez disgustado por no "haberse aguardado, antes de pasar la precitada nota". El malestar del Club Defensa se percibe en esta respuesta a las autoridades del Club Libertad, pues, en los descargos, además de señalar las virtudes de J osé María Rodríguez, se preguntaba si "ventajosamente puede representar al pueblo quien, con inquebrantable fe, lealtad y sincero patriotismo contribuyó a la defensa de ese mismo pueblo y de sus democráticas instituciones que no hacen más distinciones que las de las virtudes y talento". El Club Defensa se percataba, como lo hacía saber en la nota, que el funcionar por separado del Club Libertad lo había mantenido al margen de las decisiones y con un escaso poder real de negociación. El club se lamentaba de que "no se haya tenido la deferencia de comunicarnos la reglamentación del artículo 32 del reglamento como lo creemos natural desde que somos sucursal del Libertad, así como el no habérsenos contestado algunas notas que creemos de importancia”. 50

\section{Crónica de una decepción}

Bajo el título de “¿No juega?”, un breve texto inserto en la sección «Crónica» de La Conservación el domingo 27 de octubre advertía sobre la existencia de algún

49 El Ferro-carril, año IV, núm. 1052, Montevideo, 25 octubre 1872.

50 Ibídem. 
problema con la candidatura de J osé María Rodríguez: "Parece que se han propuesto los misteriosos no poner en sus listas a nuestro Candidato, ignoramos el por qué [sic]. Quiera Dios que no les pese". 51

La idea de integrar un candidato afrodescendiente a las listas para la Cámara de Representantes fracasó a las pocas semanas debido - según manifestaba el periódico-a los dichos de "uno de los más acérrimos Republicanos". Alguien habría afirmado que "sería la vergüenza mayor para nuestra República el que se sentara un negro en el Parlamento Nacional". ${ }^{2}$ El desengaño de los responsables del periódico La Conservación se hizo notar de inmediato a través de la radicalización de sus planteos:

“Por más que quieran negar, los hombres blancos, debemos considerar nosotros que no pueden presentándonos farsas de que todos somos iguales. Iguales sí, somos ante la ley, pero desiguales ante los egoístas. ¿ $\mathrm{Si}$ es que somos iguales y nos consideran por tal, que se han hecho esos derechos de los cuales carecemos?"53

\section{El reclamo de los redactores de La Conservación era claro:}

"[En un país en el que] reina[n] la Igualdad y la Democracia no debe mirarse en poco el color, porque esto tan solo queda para los hombres sin conciencia y sin pundonor propio. ¿De qué nos sirve que se publiquen programas liberales y democráticos, si luego se han de frustrar en ellos? ¿De qué nos sirven también el que pinten un horizonte risueño para nuestro porvenir si después nos pondrán barreras para que jamás podamos llegar a él"? 54

Pocos días después, La Conservación reforzaba su postura crítica: "Basta de sumisión, basta de silencio, que ya nuestra conciencia nos grita y nos repite que dejemos de habitar la lóbrega morada en que hemos permanecido hasta el presente". ${ }^{55}$ Estas palabras parecen haber sido un llamado a un cambio de actitud dirigido hacia el conjunto de la población afrodescendiente, y resumen, a su vez, el

${ }^{51}$ La Conservación, año I, núm. 13, Montevideo, 27 octubre 1872. En la prensa se publicaba una infinidad de listas. Revisadas las listas publicadas por los diarios Los Debates, La Tribuna, El Ferrocarril y El Siglo no se encontró ninguna en la que figurara el nombre de J osé María Rodríguez.

52 La Conservación, año I, núm. 14, Montevideo, 6 noviembre 1872.

53 La Conservación, año I, núm. 14, Montevideo, 6 noviembre 1872. Es interesante notar que, como producto de los fracasos de las negociones, la radicalización de las posturas de estos afrodescendientes se racializó.

54 Ibíd.

55 La Conservación, año I, núm. 15, Montevideo, 10 noviembre 1872. 
estado de ánimo luego de la decepción sufrida. La Conservación apuntaba sus baterías contra el Club Defensa, achacándole el no haber apoyado la candidatura de J osé María Rodríguez lanzada desde el periódico y sostenida por el Club Igualdad. "Si como ellos dijeron de que era una idea de regeneración la que dicho Club se proponía. ¿Por qué no han prestado su apoyo a la candidatura presentada por él para dignificar nuestra raza?". ${ }^{56}$

El editorial del día 6 de noviembre finalizaba instando al Club Defensa a cambiar de actitud y plegarse a las ideas promovidas desde La Conservación:

\footnotetext{
“Levante el Club Defensa la visera que tiene calada desde su fundación, deje de dejarse llevar por caprichos de un partido porque jamás conseguirán el objeto deseado; levante entre sí la bandera que nosotros enarbolamos y entonces verán un nuevo sol alumbrar nuestras cabezas y nuestra raza que tan desunida se encuentra. La veremos fuerte, y los que hoy nos miran con desprecio, temblar [sic] a nuestra presencia". ${ }^{57}$
}

El episodio ocurrido en los días previos a las elecciones del año 1872 parece haber provocado un giro ideológico en el sector de afrodescendientes que participaba del Club Igualdad. Desde las columnas del periódico La Conservación, este grupo comenzó a volcar su mirada hacia los sectores más populares de la población negra, conjugando en el contexto planteado una reflexión que incluye aspectos tanto de raza como de clase: "Si no nos basta con enarbolar nuestra bandera en silencio para derrotar a nuestros enemigos políticos, recurramos a las manifestaciones populares donde asistan todos los hermanos de raza sin distinción de partido político".58

Al final del editorial, La Conservación realizaba —una vez más—un llamado a los miembros del Club Defensa a unirse a la causa de la regeneración y de la lucha por la "libertad, democracia e igualdad": "Volvemos a repetir, de que deje el Club Defensa de formar castillos en el aire, y si quiere conseguir su idea no trate de desunir la raza y esperar de los hombres blancos apoyo, porque por más que quieran aparentar siempre serán los mismos".

\footnotetext{
56 Ibíd.

${ }^{57}$ La Conservación, año I, núm. 14, Montevideo, 6 noviembre 1872.

58 La Conservación, año I, núm. 15, Montevideo, 10 noviembre 1872.
} 
El periódico realizaba en su último número -a muy pocos días de las elecciones - un llamado final al Club Defensa a que abandonase las filas del Club Libertad del Partido Colorado para plegarse a la formación -aunque no aparece dicho explícitamente- de un "partido negro" para promover la candidatura de un afrodescendiente a la Cámara de Representantes:

\begin{abstract}
"No miremos más los colores políticos por los que nos hemos sacrificado sin obtener por nuestros sacrificios la más mínima recompensa [...] Publique el Club Defensa su separación del Club Libertad y levante la bandera de unión y encontrará el apoyo de toda una raza, cosa que no conseguirá nunca, si es que continúa en [el] silencio en que ha permanecido hasta el presente". 59
\end{abstract}

Esta compleja trama, que se configuró en los últimos meses del año 1872, tejió hilos que conducen probablemente - como ya se mencionó al inicio- a antiguas lealtades militares y políticas, diferencias en el seno de los mismos grupos de afrodescendientes, actitudes discriminatorias, etcétera.

El cisma suscitado en el Club Libertad, que hizo que los grupos principistas también se abstuvieran de participar en las elecciones, dejó a las aspiraciones del Club Defensa y del Club Igualdad con muy pocas posibilidades en la negociación. Luego de acontecidas las elecciones el diario El Siglo publicaba: "Se abstuvieron de votar en Montevideo los principistas, los blancos y los radicales, solo votaron pues, los colorados netos y los partidarios del Gobierno". 60

Andrés Seco, en la nota ya citada en la que rememora veinte años después los acontecimientos del año 1872, aclaraba que para el grupo que llevó adelante la empresa de publicar el periódico La Conservación, la opción por la autonomía en la conformación de los clubes fue una opción política en un contexto social y cultural que promovía la segregación. Decía Andrés Seco:

“El 4 de Agosto de 1872 en unión de otros amigos dábamos a luz La Conservación (veintiún años como quien no dice nada) y uno de los puntos que traté con bastante tesón fue sobre la unión de nuestra sociedad.[...] La única división era que unos vivíamos en el centro y otros fuera de la ciudad o suburbios, pero cuando se llevaba a cabo alguna reunión no había distinciones. Sin embargo, creí entonces como ahora que la base

${ }^{59}$ La Conservación, año I, núm. 16, Montevideo, 17 noviembre 1872.

60 En Oddone, 1956: 59. 
principal de nuestro adelanto y cultura tenía que ser la unión verdadera de todos sus miembros, porque a pesar de todo ya veía traslucir algo en el horizonte". ${ }^{61}$

\section{Un partido negro}

Asumiendo el fracaso de la idea de postular un candidato negro a la representación nacional en acuerdo con el Club Defensa, militantes cercanos al Club Igualdad y al periódico La Conservación llevaron adelante la noche del día 9 de noviembre una reunión en la casa de Manuel Ocampo. El objeto era "Ilevar al H. C. Legislativo, un hombre de color". 62

Los datos que se pueden recoger al respecto son muy limitados, pues la noticia de esa reunión apareció recién el domingo 24 de noviembre, día en el que estaba previsto la realización de las elecciones, y a la postre, día en que La Conservación viera la luz por última vez. ${ }^{63}$

En esa oportunidad uno de los oradores sugirió poner el nombre de Club Raza de Color al club que se estaba fundando en esa ocasión, mocionó también la citación de una nueva reunión que debía realizarse lo más pronto posible. El fracaso del proyecto del año 1872 parecería haber sido el punto de partida en la búsqueda de estrategias diferentes para lograr el objetivo de llevar a la representación nacional a un miembro del colectivo afrodescendiente. Así lo manifestó durante algunos meses del año 1873 el periódico que siguió a La Conservación: El Progresista, dirigido y redactado por los mismos Marcos Padín y Andrés Seco.

Un tema amerita ser destacado en relación a la participación política de grupos de afrodescendientes, y es el esfuerzo, la convocatoria constante realizada desde la prensa hacia la instrucción. Además de la intención de incorporar a la

\footnotetext{
${ }^{61}$ La Propaganda, año I, núm. 5, Montevideo, 5 de octubre de 1893.

62 La Conservación, año I, núm. 10, Montevideo, 9 de noviembre de 1872. Las elecciones de senadores, representantes y junta económica administrativa se realizarían -según expresa una publicación oficial- el último domingo del mes de noviembre entre las 9 de la mañana y la puesta del sol (Publicación Oficial, Elecciones de 1872, Imprenta a Vapor de El Siglo, p. 17).

63 El editorial del último número de La Conservación escrito por Andrés Seco -exredactor del periódico- muestra el desengaño de este grupo de afrodescendientes. Dice Andrés Seco: "Echemos una mirada retrospectiva sobre nuestro pasado, antes de alucinarnos con pueriles promesas que jamás se cumplirán. Desengañémonos de una vez que los hombres blancos siempre son los mismos; dejemos de ser instrumento de los enemigos de nuestra raza; no sirvamos de peldaño para que ellos suban”. (La Conservación, año I, núm. 17, Montevideo, 24 noviembre 1872).
} 
población afrodescendiente a la ideología del progreso a través de la educación, existía una razón práctica para la lucha por ejercer la ciudadanía.

Aunque existieron algunas leyes electorales posteriores -como las de los años 1833, 1853, 1858 y 1872-, estaba vigente lo dispuesto en la Constitución de 1830 y la ley electoral de ese año sobre las condiciones para la suspensión de los derechos políticos e inscripción en el registro cívico. Para formar parte del padrón electoral y poder elegir se debía ser varón, no ser menor de dieciocho años los casados, y de veinte los solteros, y saber leer y escribir. ${ }^{4}$

De todas maneras, la población negra montevideana gozó del interés de las diferentes facciones políticas que pugnaban en los períodos electorales por conseguir sus votos. Mientras los afrodescendientes luchaban por el ejercicio pleno de la ciudadanía en un contexto muy desigual de relacionamiento con el poder, el grupo vinculado al periódico La Conservación optaba por la autonomía para la conformación de un club político.

\section{Una reflexión final}

Las repúblicas nacientes en el Río de la Plata fueron construyendo sus imaginarios de nación bajo signos militaristas, criollos y de tez blanca con discursos en los que los aportes y la participación de las poblaciones de origen africano eran obviados o al menos minimizados pues se ubicaban en el relato hegemónico en la senda contraria hacia la civilización y el progreso. En este contexto es que los afrodescendientes plantearon diferentes formas de participación social, cultural y

${ }^{64}$ Las cifras de personas que en esa época no sabían firmar y eran considerados analfabetos eran importantes. El Censo del Departamento y de la Ciudad de Montevideo levantado durante el año 1889 y principios de 1890 -ya en funcionamiento la reforma de la enseñanza impulsada por J osé Pedro Varela- señala que en cifras absolutas los analfabetos ascendían a ochenta y ocho mil ciento sesenta y dos en toda la población sin distinción de sexo, nacionalidad y edad; los varones nacionales analfabetos eran veintitrés mil doscientos treinta y dos (fuente: Censo Municipal del Departamento y de la Ciudad de Montevideo, pp. 240-241). Cabe agregar que había otras causales de suspensión de la ciudadanía que podían afectar al colectivo negro, como la condición de "peón jornalero o sirviente a sueldo", o de "simple soldado de línea".

Es de suponer -aunque se carece de datos precisos- que hacia el año 1872 los porcentajes de analfabetos fueran mayores. En el Anuario demográfico de la República Oriental del Uruguay del año 1892 (publicado en 1893) aparecen datos que permiten trazar un panorama más claro al respecto. Los porcentajes de analfabetismo entre los esposos que contrajeron matrimonio en el año 1892 (veinte años después de 1872) son, entre treinta y dos a treinta y cuatro por ciento para personas comprendidas entre los dieciocho, y los treinta y cinco años de edad. Estos porcentajes comienzan a aumentar a partir de esta franja etaria con porcentajes que van desde el cuarenta y dos con cinco por ciento para los esposos de entre treinta y cinco, y cuarenta años, hasta el setenta y dos por ciento para los mayores de sesenta años (XI). 
política en un contexto de consolidación y modernización del Estado Nación. ${ }^{65}$

Ser ciudadanos en una sociedad que se complejizaba día a día significó tomar una serie de decisiones y proyectar una nueva "comunidad imaginada" - tomando palabras de Benedict Anderson-, adoptar algunas conductas, desechar otras y construir un nuevo universo simbólico.

La campaña electoral del año 1872 aparece como punto de partida a la intención de algunos grupos de afrodescendientes montevideanos de participar activamente en la construcción de la república y la democracia. Formar clubes políticos, sostener un órgano de prensa que difunda sus ideas y poder presentar un candidato que defendiera los intereses de la población de origen africano fueron cosas que ocuparon a estos grupos de negros nucleados en dos asociaciones políticas. El Club Igualdad- vinculado a sectores principistas del Partido Colorado y el Club Defensa a su ala más conservadora.

Algunas desavenencias internas, falta de pericia en el terreno político, posibles manipulaciones de los dirigentes de los círculos colorados, acciones discriminatorias y los propios cambios que se fueron produciendo, constante y rápidamente durante esa campaña electoral, fueron colocando en un lugar cada vez más marginal a las aspiraciones políticas de estos grupos de afrodescendientes.

Sin embargo, el golpe sufrido propició - a fines del año 1872- que un grupo de afrodescendientes montevideanos terminara adoptando una actitud autónoma respecto al Partido Colorado y manifestara la intención de formar un "partido negro". Utilizando algunos de los conceptos elaborados por Homi Bhabha, se estaba planteando en ese momento histórico la posibilidad de construcción de poder a partir de la diferencia. 66

65CASTRO, Cristián, "Exploraciones para una historia transnacional de la afromodernidad en América". Chicago y Sao Paolo, 1900-1940", en Hib. Revista de Historia Iberoamericana, vol. 3, núm. 1, 2010, pp. 33-49. Partiendo del análisis de la prensa de sectores de afrodescendientes en Chicago y San Pablo entre 1900 y 1940 -en una perspectiva de historia comparada y transnacional-, el autor amplía la teoría planteada por Paul Gilroy en "The black Atlantic", proponiendo la utilización del "Atlántico Negro Descentralizado" y analiza la construcción por parte de la clase media negra urbana de su propia versión de la modernidad, en lo que denomina "afromodernidad".

66 BHABHA, Homi, El lugar dela cultura, Buenos Aires, Manantial, 2002, p. 19. 


\section{Bibliografía y Fuentes}

\section{Bibliografía}

ANDREWS, George Reid, Los afroargentinos de Buenos Aires, Buenos Aires, Ediciones de la Flor, 1989.

- Negros en la nación blanca: historia de los afrouruguayos 1830-2000, Montevideo, Linardi y Risso, 2010.

BARRÁN, José Pedro, Apogeo y crisis del Uruguay pastoril y caudillesco. 18391875, Montevideo, Ediciones de la Banda Oriental, 2011.

BHABHA, Homi, El lugar de la cultura, Buenos Aires, Manantial, 2002.

CASTRO, Cristián, "Exploraciones para una historia transnacional de la afromodernidad en América". Chicago y Sao Paulo, 1900-1940", en Hib. Revista de Historia Iberoamericana, vol. 3, núm. 1, 2010, pp. 33-49.

FERNÁNDEZ SALDAÑA, J osé María, Diccionario uruguayo de biografías, 18101940, Montevideo, Editorial Amerindia, 1945.

GELER, Lea, Andares negros, caminos blancos. Afro-porteños, Estado y Nación Argentina a fines del siglo XIX, Buenos Aires, Prohistoria Ediciones/ TEIAA, 2010.

GOLDMAN, Gustavo, Lucamba: herencia africana en el tango (1870-1890), Montevideo, Perro Andaluz Ediciones, 2008.

GONZÁLEZ BERNALDO DE QUIRÓS, Pilar, Civilidad y política en los orígenes de la Nación Argentina. Las sociabilidades en Buenos Aires, 1829-1862, Buenos Aires, FCE, 2001.

ODDONE, Juan Antonio, El principismo del setenta: una experiencia liberal en el Uruguay, Montevideo, Instituto de Investigaciones Históricas/ FHC, 1956.

ZUBIZARRETA, Ignacio y ETCHECHURY, Mario, "«Aquí no hay partidos»: estudios y perspectivas sobre las facciones y grupos políticos del siglo XIX hispanoamericano", en: Illes i Imperis, núm. 17, Barcelona, Universitat Pompeu Fabra, 2014.

\section{Fuentes éditas}

BOLLO, Luis Cincinato, 1893, Anuario demográfico de la República Oriental del Uruguay, Año III-1892, Montevideo, Tipografía Goyena, 1893.

Censo Municipal del departamento y de la Ciudad de Montevideo, Capital de la República Oriental del Uruguay, Edificación, Escuelas, Población e 
Industrias, Levantado por resolución de la Junta EconómicoAdministrativa en los días 25 de setiembre, 5 de octubre, 18 de noviembre de 1889 y 25 de enero de 1890, Establecimiento Tipográfico Oriental, 1892, Montevideo.

DE MENDIZÁBAL, Rodolfo E.: La política del porvenir. Artículos al correr de la pluma. Publicados en El Mercantil, Buenos Aires, Imprenta especial para obras de Pablo E. Coni, 1874.

Elecciones de 1872, Publicación Oficial, Imprenta a vapor de El Siglo, 1872, Montevideo.

Guía General Comercial de La Tribuna para el año 1877, Montevideo: imprenta a vapor de La Tribuna, 1877.

Reglamento de la Sociedad Pobres Negros Orientales, Montevideo, Imprenta de La Tribuna, 1869, Montevideo.

\section{Prensa}

El Ferro-carril, Montevideo, Imprenta El Ferro-carril, revisado año 1872

El Siglo, Montevideo, Imprenta El Siglo, revisado año 1872.

La Conservación, Montevideo, Establecimiento Tipográfico La República, revisado año 1872.

La Democracia, s.n, revisado año 1872.

La Paz, Montevideo, Establecimiento Tipográfico, revisado año 1872.

La Propaganda, s.n, revisado año 1893.

La Tribuna, Montevideo, Imprenta de La Tribuna, revisado año 1872.

Los Debates, Montevideo, s.n, revisado año 1872. 